\title{
DINÁMICA DEL MITO EN O GUESA DE SOUSÂNDRADE
}

Cesar Augusto López Nuñez*

RESUMO: Um dos temas mais refletidos sobre $O$ Guesa de Sousândrade é o mito e sua importância na construção do poema. Isto quer dizer que o processo de composição foi consequência de uma perspectiva sobre a matéria do mito e sua relevância na construção do mundo (real e possível). No caso do poeta maranhense, devedor em grande medida da tradição romântica e seu impulso na formação da nação brasileira, temos uma peculiar forma de recorrer ao mito como entidade proteica que pode abarcar uma grande quantidade de fenômenos humanos e, inclusive, não-humanos para explicar a heterogeneidade que estabelece o escritor entre o mito e a literatura, e como consegue traçar uma linha de fuga da sua tradição culura como uma ponte com as urgências da modernidade.

PALAVRAS CHAVE: Mito; Estética; Política; Sousândrade; O Guesa
* usatuilusion_1993@hotmail.com

Licenciado en Literatura por la Universidad Mayor de San Marcos con la tesis Óscar Colchado Lucio: la propuesta cosmopolítica de Rosa Cuchillo (2015). Actualmente realiza estudios de maestría en Teoría iteraria y Literatura comparada en la Universidad Federal de Minas Gerais gracias al apoyo del CNPq.

RESUMEN: Uno de los temas más reflexionados sobre $O$ Guesa de Sousândrade es el mito y su relevancia en la construcción del poema. Esto quiere decir que el proceso compositivo se debía a un tipo de perspectiva sobre la materia del mito y su importancia en la construcción del mundo. Para el caso del poeta maranhense, deudor en gran medida de la tradición romántica y su impulso formativo de la nación brasileña, tenemos una peculiar forma de apelar a lo mítico como entidad proteica que puede abarca una gran cantidad de fenómenos humanos, e incluso no-humanos, para explicar la heterogeneidad de América Latina. En este Uns, par explicar la hesome entido, intentaremos explicar la relación que establece el escritor entre mito y literatura, y cómo consigue delinear una línea de fuga de su tradición cultural como un puente con las urgencias de la modernidad

PALABRAS CLAVE: Mito; Estética; Política; Sousândrade, O Guesa 
1. Fuera de lo que pudo haber propuesto Lyotard sobre la caida de los grandes relatos los haya tenido $y$ sobre todo que no haya ar sobre todo que no haya acreditado en relativización absoluta $y$ su relatización absoluta es un gran relato de la desesperanza, aunque radical de los sistemas.
La cuestión del mito tiene una vigorización en momentos de tránsito cósmico. Saltos míticos como la adopción de las divinidades griegas en las prácticas públicas y privadas de Roma le dieron al imperio un prestigio y un linaje olímpico como estableció Ovidio en la Eneida. La invasión española echó mano de las Sagradas Escrituras para localizar el posible origen bíblico de los pobladores de América y su participación en la Historia de la Salvación cristiana y, por su parte, las diversas etnias vencidas recurrían a su bagaje narrativo para explicar la llegada de los blancos barbudos junto a su maquinaria que dejaba en un mutismo doloroso a los creadores y protectores locales. Lo mismo sucedió en el Iluminismo y su fe en la luz que vence a las tinieblas de la ignorancia; la luz del entendimiento que quiebra las supersticiones colocando al hombre, ya no como creación, sino como conductor supremo de su destino y de sus circunstancias sacando de la jugada a la divinidad. Más adelante, el Romanticismo conquistaba el espacio del corazón del hombre y del pueblo para estatuir orden en la comunidad y plasmar al Estado como la máxima muestra del desenvolvimiento del espíritu. En otras palabras, la humanidad ha experimentado muchos cosmos o lecturas del cosmos que han sido guiadas de una $\mathrm{u}$ otra forma por narrativas compartidas ${ }^{1}$. La comunidad no es solo imaginada como bien dijo Benedict Anderson, sino, y sobre todo, sentida. No existe imagen unificadora sin narración que no intente dirigir los cuerpos de un colectivo. Sobre estas dos últimas premisas es que se guiará nuestro artículo².

Dentro de la larga estela de grandes y pequeños mitos que forman redes infinitas y heterogéneas nos queremos detener en un intento, probablemente fallido en su época, de sintetizar (más no reducir) una experiencia de transformación de cosmos, además de una propuesta de lectura de lo que se avecinaba para un grupo social específico. Hacemos referencia a $O$ Guesa de Joaquim de Sousa Andrade o Sousândrade Esta obra incompleta de trece cantos, perteneciente a Romanticismo Brasileño, respondió, sino de manera genial, en el sentido más romántico del término, creativamente a dilema de un país que pasaba a formar parte de las repúblicas libres de nuestro continente. Para tal efecto, el poeta, por un lado, recurrió a la mitificación del suceso libertario, como varios de sus contemporáneos, mientras que, por el otro, e mismo principio mítico lo distanció al punto de convertirlo en una referencia estética de nuestro presente.

Si bien el mito jugó un rol fundamental en el intento de crear una imagen de la "brasileñidad" esta tarea estuvo en lazada a la perspectiva del Imperio que consiguió hacer gravitar el poder de los creadores en torno a sus intereses: el Indianismo es muestra de ello. El caso vital de Sousândrade en referencia a lo anterior es que él no consiguió insertarse en esa dinámica ${ }^{3}$ y logró, posteriormente, tener conciencia
2. Se puede considerar este trabajo como continuación del artículo "Experimentar con la literatur desde un pensamiento otro" publicado por esta misma revista y presente en la bibliografía.

3. Su petición de financiamiento para estudios fue negada por la 
4. El primer trabajo sistemático sobre la producción artística soousandradina fue realizada por los hermanos Augusto y Haroldo de Campos.

5. Consideramos al mito como dialógico puesto que su realidad responde a relacionar una cantidad amplia de referencias, mientras que lo monológico u occidental pretende homogeneizar o borrar rastros de humo que no be adecustros de propuestas.

6. El Guesa significa errante y es un niño arrebatado del seno familiar y formado por los sacerdotes (Xeques) de la etnia Muisca, a la que pertenece. Luego de una esmerada formación, ya en la adolescencia, pasaba por un camino llamado Suna en dirección a su sacrificio al dios solar Bochica. Corazón y sangre eran ofrecidos para recomenzar un nuevo ciclo solar. Sousândrade encontró dicha narración en dos libros: L'Univers. Histoire et description de tous les peuples (1837) y Vue des cordillères, et monument des peuples indigènes de l'Amerique (1810). de la limitación a la que se sujetaba quien lo hacía. A diferencia del Indianismo romántico de un Gonçalves Dias o un José de Alencar, el autor de $O$ Guesa avisoró, con limitaciones, claro, un indigenismo romántico, por así decirlo. Su intento no fue remitirse al pasado ideal de la tierra brasileña y el orgullo de sus etnias ya extintas ni tampoco aspiró al mestizaje armónico, sino que desde un indígena, el Guesa o el Errante, alimentado por el periplo del poeta, expuso una denuncia del estado de vida al que fueron empujados los nativos y la degradación que devendría del éxito del capitalismo naciente en Nueva York. Hacemos referencia a los harto comentados cantos II y X.

Esta tensión problemática que se genera en el seno de la obra de Sousândrade incidió directamente en su incomprensión y en su olvido parcial dentro de la tradición literaria brasileña ${ }^{4}$. Pero ahora remitámonos a la cuestión mítica en la que varios han reparado no sin dejar de aclarar que $O$ Guesa es una marca tensiva en la que se debaten la tradición y lo moderno con no pocas dificultades: hecho propio de la proyección del mito sobre el mundo por venir y práctica real fuera del pensamiento monológico ${ }^{5}$. ¿De dónde parte $O$ Guesa? ¿Cuál es su principio rector? El poeta responde a estas dudas en su "Memorabilia" a la edición del libro de 1876. En primer lugar, considera el dato del Guesa, de los trabajos etnográficos de Alexander Von Humboldt, como una leyenda ${ }^{6}$. En segundo lugar, explica que la "natureza singela e forte" del texto se aúna a la "natureza própria do autor". Por último, responde a sus críticos sobre el Suna o camino sacrificial que propone en el poema alegando que la nueva ruta se condice con la modernidad decimonónica.

Bajo estas tres premisas es que se debería realizar una primera aproximación al poema y sobre las mismas se debería discutirlo. Para comenzar, Sousândrade es lo suficientemente cauto para no asumir la veracidad total del texto Humboldtiano al calificarlo de leyenda, pero, por otro, lo toma como piedra de toque para desplegar su proyecto estético-político ${ }^{7}$. Esta primera tensión nos exige aclarar que el dato del que se vale el poeta maranhense no es ni leyenda ni mito, sino un rito; es decir, la puesta en práctica de una narración rectora a la que se enlaza la vida del autor para encarnarla ${ }^{8}$, curiosamente. Sousândrade es el Guesa moderno. No solo tenemos en el poema la reconversión del dato etnográfico, sino una acomodación vital del poeta a la historia. El movimiento poético realizado en el texto no es unidireccional, sino bidireccional, tenso e intenso ${ }^{9}$. Coherentemente con el romanticismo, la vida de Sousândrade es ritualizada, elevada a una sacralidad secular puesto que el nuevo mundo que esperaba con ansias y que consiguió ver fue el de la vida republicana, el nuevo espacio de la esperanza según el poeta.

Por otro lado, el segundo tópico reafirma nuestra idea anterior en el nivel de la creación verbal. Existiría una
7. Uno de los primeros extranjeros en acertar sobre el americanismo sousandradino fue el peruano Ricardo Palma en una carta enviada a Juan Zorrilla de San Martín en la que hace énfasis en la singularidad expresiva de continente: «Desde este punto de vista, la Araucana de Ercilla, O Guesa errante de Souza Andrade (sic.) y Tabaré, son los poemas que, en mi concepto, satisfacen más cumplidamente el ideal del americanismo literarion (Mis últimas tradiciones peruanas. Cachivachería, p. 430).

8. Sousândrade quedó huérfano muy temprano y fue un viajante muy observador. Es posible que estos dos datos hayan servido para su identificación con el Guesa.

9. Entendemos intensidad o intensidades como la puest en escena de diversas fuerzas agenciadas en el cuerpo textual. Claro ejemplo de ello es el desfile de una cantidad considerable de personajes en el poema $y$, sobre todo, en los cantos II y X.
EM TESE
BELO HORIZONTE
v. 22
N. 2
MAIO-AGO. 2016
NUÑEZ. Dinámica del mito en 0 Guesa de Sousândrade
p. $83-94$ 
consubstancialidad entre el poema y el autor. No le basta al poeta identificarse y hacer una alianza con el Guesa, sino que la forma del texto se corresponde con la dinámica subjetiva del creador. El combate sousandradino busca quebrar las fronteras entre el sujeto y el objeto, entre la ficción y la realidad con el objetivo de que se comprenda que su proyecto poético tenía pertinencia en la construcción del nuevo mundo que se avecinaba y que él lograba percibir y expresa como primicia. En otros términos, el nuevo panorama político merecía un escritor acorde con sus premisas de las que Sousândrade se asumía conocedor idóneo.

Ya en su tercer tópico el camino sacrificial se universaliza por ampliación permitiendo al poeta hacer un corte transversal a una diversidad vasta de estratos del mundo con e objetivo de generar no solo una crítica al estatus quo saliente (la monarquía), sino al naciente (el capitalismo). Los do cantos más famosos de O Guesa no solo son producto de una intuición vanguardista, sino, y sobre todo, de una evaluación total del mundo: economía, política, historia, sociedad, arte etc. Quizá tenemos aquí una fidelidad más allá de lo pensado al Suna, puesto que, si el movimiento sacrificial tiene como punto culmen la restitución o manutención del orden cósmico, todos sus niveles merecen una revisión de su estado. Podemos concluir de esta breve reflexión de las máximas de O Guesa que lo que se realiza en sus versos es una alianza con el mito, la reactivación, actualización y potencialización de sus capacidades.

Uno de los primeros en corroborar el último aspecto mencionado es Luíz de Costa Lima quien afirma que Sousândrade es fiel a la dinámica del sentido mítico ${ }^{10}$. Por otro lado la in vestigadora Rita Cássia de Oliveira menciona lo siguiente: "a transmutação de ação em poesia por meio do mythos foi elaborada do modo magnífico pelo Sousândrade ao elevar ao plano do poético a dimensão mítica dos índios da Colômbia os Muíscas" ${ }^{11}$. Nos gustaría agregar que la dimensión poética se eleva al plano mítico por el afán de renovación estética y su pertinencia en la configuración de la nueva vida política de la nación brasileña. El intento osado del autor de $O$ Guesa es restituir a la poesía su lugar en la república, siglos después de la expulsión platónica, al reconocerle su poder performativo. Que esta fe en el arte verbal como instrumento crítico y de poder haya encontrado probablemente su último aliento ad portas del siglo XX en Sousândrade es un tema que no podremos tocar en esta ocasión más que tangencialmente.

Dentro del juego mito/obra es evidente que el enlace es el artista en tanto artesano, punto sobre el que cruzan infinitas líneas que adquieren consistencia en un evento literario donde el mito deviene poesía y la poesía deviene mito. Importante mencionar que esta afirmación es obvia solo en apariencia puesto que el efecto crítico de la obra solo es
10. LIMA. O campo visual de uma experiência antecipadora: Sousândrade, p. 480.

11. OLIVEIRA. O poema O Guesa de Sousândrade, à luz da hermenêutica de Paul Ricoeur, $\mathrm{p}$. 47. 
12. La recuperación de algunas obras para el canon siempre va marcada por un desfase socio-histórico más profundo en relación a las canonizadas. Recordamos, por ejemplo, el caso de Guaman Poma de Ayala y su Nueva Corónica y Buen Gobierno que no obtuvo lo que esperaba en los tiempos de la colonia, además de su improbable llegada a la España de Felipe III. En este sentido, su recuperación prest cuerda para los lectores de un objeto interesante, histórico, pero poco aceptable como instrumento político.

13. “Elementos da tradição judaicohebraico-cristã (sic), associados à mitologia indígena, apresentados como dimensões integrantes na formação de uma nação que traz em seu bojo a história milenar de civilizações indígenas extintas, mas que formam a grande história da Amazônia pan-americana. Uma junção de ritos opostos e contraditórios num espaço mítico errante rumo à tragédia do Novo Mundo. Este é o mundo do Guesa" (VIANA DA SILVA. Ecos ameríndios em Sousândrade, p. 90). posible en esa pauta de oscilación que Sousândrade conquista. En realidad, se aspira al retorno de la validez estética en el plano político. Es decir, la "impotencia” de lo mítico, al ser cuestionada por la poiesis, conseguiría salir de su situación aparentemente estanca y apelar al sentir de los lectores y, por ende, a la formación de la nación brasileña. Bien sabemos que esto no ocurrió como esperaba nuestro poeta y que su retorno a la escena académica comienza, principalmente por su "concretismo"12.

Si hablamos de líneas míticas fundamentales, el modelo del Guesa le permitió a Sousândrade relacionar otras míticas en el proceso de expansión de las potencialidades de su narrativa base ${ }^{13}$. Es la figura del camino el tenor que no desaprovechará el poeta y que le permitió, desde diversos puntos de vista, ser una línea de fuga de su tradición. El viaje del Guesa-Sousândrade arrastra una gran cantidad de elementos hasta conseguir una desterritorialización inaudita para su tiempo. En este sentido, podríamos decir que el caos que muchos críticos anotan como defecto en su obra es el principio de su dinámica. La ilegibilidad en muchos casos es fruto de la exigencia enciclopédica y contextual que exige de sus lectores. No obstante, los trabajos de los hermanos Campos, su biógrafo Frederick Williams, Luiza Lobo y Juan Carlos Torres-Marchal dan valiosas pistas sobre los sentidos que abre $O$ Guesa.
Continuando con la idea de apertura dialógica que se nos presenta en el camino-línea de fuga del Guesa tenemos, pues, que el joven elegido para ser sacrificado tiene características de Inca, de Prometeo y de Jesús. No bastaba con lo muisca para explicar América, sino con todo lo que ella tenía y prometía. En este nomadismo de sentido es que descubre al líder del Tahuantinsuyo como imagen prototípica del continente sin dejar de lado el antecedente griego del civilizador titán y finalmente al Mesías como penúltimo guía de la humanidad dado que el Guesa redivivo en el Poeta expresa el horizonte de las tierras conquistadas y liberadas del Sur. Esta acumulación de potencias expresa no solo la continuidad del pasado en el presente, sino de su actualidad en la formación del pensamiento futuro que América necesita y posee a su vez. Desde este punto de vista, el mega-mito que se construye es también una inmensa anamnesis. El Guesa-Inca-PrometeoMesías sería la encarnación heterogénea de lo universal ${ }^{14} \mathrm{y}$ así "O sincretismo mítico apresenta-se [...] como uma visão crítica em relação à situação do homem na sociedade". ${ }^{15}$ No es en vano, entonces, el recargado estilo sousandradino, sino consecuencia de las transformaciones que experimentaba su mundo. Incluso nuestro poeta afirma que la forma del Canto $\mathrm{X}$ fue producto de la impresión que le generaban los periódicos de Nueva York ${ }^{16}$. Una vez más nos acercamos a esta negociación constante entre mundo y creación de la que no se
14. Frederick Williams nombrará estas coincidencias heroicas de Titanismo siguiendo las propuestas del checoslovaco Vaclav Cerny referentes al romanticismo europeo (Sousândrade: vida e obra, p. 151-153).

15. PEREIRA. Tradição e modernidade em Sousândrade, p. 46 .

16. Das "Memorabilia que introduzem o canto VIII". Em: Re Visão de Sousândrade, p. 197. 
sustrae Sousândrade ya que $O$ Guesa no es una obra escapista salvo para quebrar un orden creativo impuesto.

Sumado a lo dicho líneas arriba, el investigador Danglei de Castro afirmará los siguiente: "O Guesa torna-se [...] uma crítica à excessiva idealização do espaço interno imposta pela vertente romântica epigonal e, sendo assim, organiza-se de forma a denunciar um olhar mais crítico e racional face esse cânone". En otras palabras, todo aquello que pone en movimiento el poema lo conduce a una visión crítica radical de su entorno. Aquel corte transversal del que hablábamos solo es efectivo en torno a las intensidades que se concentra en el cuerpo poético y así se generan diversas revoluciones que abren constantemente las posibilidades expresivas del poema. Ya no solo hablaríamos de cortes que realiza el texto, sino de la unión de distintos círculos o, también, la exposición de diversas relaciones de sentido no percibidas hasta entonces.

A modo de resumen, diríamos que la recuperación de mito por parte de Sousândrade tenía claro la renovación del sentir y la concientización de las circunstancias políticas de un presente por fenecer y de un futuro naciente. He aquí la tensión fundamental del texto que le brinda ese vigor complicado para la crítica. El tríptico mito, estética y política es manejado en relación a dos tópicos históricos que consideró urgentes: la situación del indígena brasileño y la amenaza deshumanizante del capitalismo en la que el punto medio no es solo la extensión bio-textual de O Guesa, sino la capacidad de absorción del poeta, su canibalismo ${ }^{17}$. Podemos ahora abordar los cantos que se refieren a estas dos puntas de lanza que Sousândrade no teme enfrentar en un nivel de expresión alto. Conocidos como "Danza de Tatuturema" e "Infierno de Wall Street", los cantos II y X, respectivamente, han sido sujetos a interpretaciones que van desde lo estético verba (como anticipación de la vanguardia) hasta la imposibilidad de la expresión u obra nonsense. ${ }^{18}$

En nuestro caso, proponemos que Sousândrade apela al mito para abrir las puertas a un nuevo modo de sentir o visualizar el mundo y de hacer política; una aún no conocida en su tiempo. La primera crítica que nace de esta postura es que la llegada del conquistador generó una degradación del indígena como lo muestra en el ritual báquico al dios Juruparí en el Canto II. La novedad de esta puesta en escena, que se condice con el infierno dantesco y la noche de Walpurgis goethiana, gira en torno a la desestratificación de diversos niveles de conocimiento para arrancar una mirada total a partir de la multiplicación de perspectivas. La primera estrofa de este "infierno" nos permite abordar lo anterior:

\section{(MUÇURANA histórica:)}

- Os primeiros fizeram

As escravas de nós;
17. Siendo fieles a este término, la canibalización no solo tiene que ver con el aprovechamiento y adecuación de recursos externos, sino, y sobre todo, de subjetividades o perspectivas.

18. CERNICCHIARO. SousândradeGuesa em inferno do "Wall Street": poéticas políticas. 
19. Canto II, vv. 249-254. Todas las citas de $O$ Guesa son tomadas de la edición presente en la

bibliografía.

20. Algunos trechos de $O$ Guesa podrían leerse en clave feminista.

21. Canto II, vv. 273-278.
Nossas filhas roubavam,

$$
\text { Logravam }
$$

E vendiam após. ${ }^{19}$

La Muçurana histórica es la voz étnica de la memoria del abuso cometido contra las mujeres inmediatamente después de la invasión europea. ${ }^{20}$ Este dato no es nada gratuito ya que el ritual criticado es de fertilidad y Sousândrade ve en él las huellas de degradación generadas por la presencia del hombre blanco que aprovecha las circunstancias para "festejar" y embriagarse como podemos notar en las siguientes partes:

(Coro dos indios:)

- Mas os tempos mudaram,

Já não se anda mais nu:

Hoje o padre que folga,

Que empolga,

Vem conosco ao tatu. $^{21}$

La desnudez acostumbrada ha sido desterrada por el cura que folga y se anima a intervenir a una fiesta que no le incumbe y de la que reclama placer dionisiaco:

(Padre EXCELSIOR, repondendo:)

Indorum libertate

Salva, ferva cauim
Que nas veias titila

Cintila

No prazer do festim! ${ }^{22}$

En tres momentos del poema se nos presenta un ambiente caótico, pero la tensión que genera está sucesión de voces no es más que el llamado a la reflexión sobre el espectáculo y sus participantes: la mujer como enclave del placer desmedido, el colectivo (coro) que explica las nuevas costumbres y el cura que justifica en latín su desenfreno. Es decir, la estrategia tensiva de la multiplicación de personajes apuntaría a cuestionar el estado de las cosas actuales al relativizarlas ${ }^{23}$ en puntos impensados. Al igual que Dante y la crítica teológico-moral de su sociedad en la Comedia ${ }^{24}$, Sousândrade emplea esta danza "infernal" para advertir la crisis vivida y el deber evitarla. Así, en algún sentido, las obras cumplen un rol profético. Por un lado, las diferencias entre uno y otro autor residen en las velocidades con las que cada uno compone y los espacios de los que echan mano. Por otro lado, el vigor mítico es el mismo: cuestionar a partir de una narración el modo de vida puesto en marcha por sus contemporáneos y reconducir estás capacidades para el porvenir.

Pero a Sousândrade no le basta, como a Dante también, con realizar una recopilación de la contemporaneidad, sino aprovechar al máximo la vitalidad del mito que pone en jaque
22. Canto II, vv. 307-312.

23. Utilizamos el término relatividad en el sentido de relación y no solo de desestabilización absoluta.

24. Importante recordar un crítico "modesto" como Balzac y su Comedia humana. 
25. Canto II, vv. 428-434.

26. Canto II, vv. 350-355.

27. Canto II, vv. 476-481.

28. Canto II, vv. 497-499.

29. Canto II, vv. 619-624.

30. Canto II, vv. 756-761.

31. Canto II, vv. 900-905

32. Canto II, vv. 458-463. el tiempo y el espacio. De esta forma, aparecen relativizaciones como aquella en la que aparece Timón de Atenas, personaje shakespeariano, leyendo a Camões y Virgilio ${ }^{25}$ quizá en el intento de aprender de ellos ya que este personaje fue adulado al punto de perder sus riquezas y experimentar el autoexilio. Otro personaje interesante que también sostiene un parlamento desde el mar es Gonçalves Dias ${ }^{26}$ a quien el poeta marañense admiraba y que de cierto modo critica por su adhesión al sistema de representación monárquico poco afín a la posición de este Canto. Es así que sobre la tarima del caos crítico desfilan Rodrigo de Triana ${ }^{27}$, Napoleón ${ }^{28}$, Bruto $^{29}$, Jonás ${ }^{30}$, entre otros, hasta culminar con la voz de la Esfinge. ${ }^{31}$

En medio de estas oscilaciones, de ritmos narrativos, Sousândrade va más lejos que Dante y Goethe, y se aproxima a un perspectivismo, avant la lettre, literario. Nos referimos a los parlamentos siguientes:

(Ecos das nuvens:)

- Há trovões no Parnaso,

São dos cumes a luz;

Quando vem Fomagata,

Em cascata

Terra-inundam tatus ${ }^{32}$
(VIOLA rindo:)

- Deste mundo do diabo

Dom Cabral de apossou,

E esta noite d'Arabia

Astrolábia

Desde então se bailou. ${ }^{33}$

Con estos fragmentos queremos ejemplificar esa real apertura dialógica a la que el poeta somete su creación. No solo hombres de ficción, reales y de una historia lejana al tiempo de enunciación participan sobre un mismo plano de expresión, sino también seres no-humanos como ecos de nubes o una viola, entre otros. Este "irracionalismo", por as decirlo, responde a un acontecimiento y no a un objeto por estudiar. El libro se llena de subjetividades de manera desbordante para presentarse como estrategia de resolución del problema humano que Sousândrade asume en si $^{34}$. Es verdad que puede parecer pretenciosa no solo nuestra propuesta, sino la del propio autor, pero que esta obra le haya tomado más de treinta años de su vida y que en el proceso haya asumido las consecuencias de la experimentación justifican por un lado lo que decimos. Otro aspecto que refuerza nuestra afirmación se puede situar en la reflexión de críticos literarios contemporáneos como Terry Eagleton, la complicada filosofía de Gilles Deleuze y Félix Guattari que, por veces, puede parecer esotérica, y las aproximaciones antropológicas
33. Canto II, vv. 482-487.

34. Terry Eagleton contempla estas posturas sobre la literatura: por un lado como objeto y por otro como acontecimiento (event) 0 estrategia (El acontecimiento de la literatura, p. 240) 
35. Canto X, vv. 2073-2078

36. Canto X, vv. 2852-2858 post-estructurales de Eduardo Viveiros de Castro de las que hemos echado mano a lo largo de nuestro artículo.

En el caso del Canto X el sentido es acelerado, aún más como podremos notar en los siguientes episodios:

(Astronómicas influencias, CANCRO e CAPRICORNIO:)

- São freeloves Ursas do Norte;

Ped'rasta o Cruzeiro do Sul..

= A yanky! $\mathrm{O}$ carioc!

Stock, stock,

Minotauro e de Io o olho azul! ${ }^{35}$

(Gotas magnéticas nos ares à manipulação de inmortais? um morto

redivivo contra a vontade dos assassinos:)

- 'Não fales!' que por um princípio

Vai Codrus em louco morrer!...

= Codrus? Louco? padres

Compadres

Co'as vossas nódoas Deus não quer! ${ }^{36}$

Las constelaciones de Cáncer y Capricornio discuten las prácticas inmorales de la mujer norteamericana (freeloves) y el encuentro entre el presidente de los EE.UU. y don Pedro II (yanky/carioc). En otro momento, y de mayor dificultad interpretativa aún, gotas magnéticas y un muerto resurrecto conversan sobre la dignidad de la muerte y la vida significados en la figura de Codro, último rey de Atenas que según el oráculo no debía ser muerto para que la ciudad cayera en manos invasoras. Este, sabiendo el anuncio, se viste de mendigo para morir a manos del enemigo y así impedir la toma de su reino. Esta muerte honorable es recordada en la estrofa para dar énfasis al valor de la oblación y su sentido en el mapa sacrificial que traza el viaje del Guesa.

Como se puede apreciar, lo más importante del mito es lo que se puede establecer en el medio, entre el principio y el fin del camino para completar el cuadro del mundo. En este sentido, lo mítico debe ser siempre poblado para arrancar una siempre difícil conclusión del estado de las cosas o como diría Terry Eagleton:

[...] los mitos no cumplen con su función de un plumazo, sino como un proceso estratégico, cuando un conjunto de antítesis se transforma en otro hasta que este, a su vez, en un tercero; cuando una contradicción es mediada solo para hacer nacer otra, un elemento es desplazado por otro que a su vez está desplazado, y así sucesivamente. También opera aquí una "intertextualidad” incesante, pues un texto mitológico canibaliza a otro hasta que, a su vez, se recicla mediante un tercero. El significado inconsciente de un mito, señala Lévi-Strauss, es 
37. EAGLETON. El acontecimiento de la literatura, p. 247.

38. Cf. BRÉHIER. A teoria dos incorporais no estoicismo antigo.

39. DELEUZE; GUATTARI. ¿Qué es la filosofía?, p. 27. el problema que pretende resolver; y para alcanzar dicha solución despliega mecanismos tan inconscientes como la imagen, la trama y la narración. Sin embargo, se nos advierte que no pensemos que la relación entre consciente e inconsciente, entre trama y problema, es de reflejo u homología, sino de transformación ${ }^{37}$.

El tercero aparece en la conjunción de infinitas variables y de sucesivos desplazamientos de sentido, el tercero es la totalidad de la obra, el evento o estrategia que busca sobre todo preguntar, cuestionar al lector a través del sentir en un proceso de transformación no solo de la subjetividad del destinatario, sino del cosmos: no en vano trópicos y partículas hacen su aparición en la trama textual.

Centrándonos en el tercero que abre la potencia mítica, podríamos creer a primera vista que es el personaje Guesa y sus agenciamientos con otras referencias arquetípicas; sin embargo, su funcionalidad tiene una razón más cercana a lo incorporal como entiende Émile Bréhier ${ }^{38}$ y que continuarán sus discípulos Foucault, Deleuze y Derrida. Lo que se quiere explicar con esto es que el tercero es "Real sin ser actual, ideal sin ser abstracto" 39 . Tenemos frente a nosotros un entre que establecería una alianza con el receptor como todo mito procura: ser practicado. Solo a partir de este dato podemos entender al Guesa-Sousândrade que expone al máximo su sensibilidad para aproximarse a otras sensibilidades como petición de corporificación del mito actualizado. Cada uno de los personajes que desfila en los cantos II y X es un percepto que el artista consigue ex-presar para renovar una estesi que aún continúa en movimiento, pero que ha sido perdida de vista en la práctica cotidiana, a pesar de que mantiene su poder performativo.

Todo este recorrido solo obtiene su sentido si recordamos el pensar indígena. En éste, el mundo de los muertos, de los vivos y de los espíritus se encuentra en relación constante de modo que cada uno se afecta en una retroalimentación infinita. El chamán, por su parte, es un lector y traductor privilegiado de estas potencias heterogéneas en pro de la comunidad. El animismo que hemos querido resaltar en algunos pasajes de $O$ Guesa citados se corresponderían con nuestro intento de aproximarnos al mito ya no solo como un objeto, sino como un sujeto $^{40}$ que lee el mundo; lejos de la pasividad de un hecho catalogable. De esta forma, Sousândrade sería uno de esos primeros escritores que nosotros llamamos de artesanos cósmicos, porque se permitieron el delirio ${ }^{41}$ como principio de reacción frente a una configuración de mundo totalitaria. Es decir, la valorización de diferentes dimensiones que actúan en el presente y que permiten el futuro. Así, la visión ritual desplegada por el poeta nos dejaría "indigenizar" de algún modo al mismo Dante quien recurrió a sus
40. Es sujeto no en el sentido antropocéntrico del término, dado que no es un ser humano, sino como capacidad de enlazar perspectivas al hacerlas actuar en relación a una comunidad.

41. El mismo poeta lo dice de la siguiente forma: "Canicular

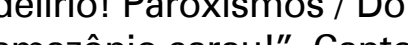
au!", Canto II, vv. 906-907. 
42. En este trabajo hemos hecho enfasis en la repercusión del mito sobre el autor y su obra. Por tal razón, no hemos anotado os límites del texto que, sin

duda, presenta y que esperamos exponer en posteriores trabajos. mitos para dar una mirada total de su cosmos animando, consecuentemente, a una batería de perspectivas y reconociendo su valor de verdad. La noche de Walpurgis a la que recurrió Goethe y a la que se remite Sousândrade creemos que no necesita más explicación según el tono de nuestra lectura.

Para finalizar nuestro trabajo, y a modo de resumen, quisiéramos hacer énfasis en la fuerte relación entre el mito, e sentir y el hacer. El primero como ordenación parcial del caos que exige una apertura delicada, casi quirúrgica, de la estesis de una sociedad y, como resultado de esto, la organización de sus poderes en la dimensión política. Según lo dicho, $O$ Guesa sería uno de esos grandes intentos ${ }^{42}$ de hacer emerger en medio de la "deformidad" del continente una narración que abarque su espectro de acción tomando en cuenta lo vivido por la humanidad hasta ese entonces, pero comenzando por la singularidad de las tierras del sur. Así planteadas las partes, el mérito sousandradino sería el de haber salido de paradigma normativo de su tiempo en pos de nuevos afectos por traducir colocándolo en una actualidad que vislumbró en su trabajo y que mantiene consonancia con temas aún no abordados en la agenda urgente de nuestro tiempo. Este perfil descolonial de nuestro autor no hubiese llegado tan lejos sin la ayuda de la permanencia mítica con la que no dudó establecer una negociación y que esperamos haber dejado en claro: América Latina debe personificar muchas de sus voces invisibilizadas para entablar un trato simétrico con lo occidental y poder iluminar sus lados oscuros en la exploración de un mundo común.

\section{REFERENCIAS}

BRÉHIER, Émile. A teoria dos incorporais no estoicismo antigo Trad. Fernando Padrão de Figueiredo e José Eduardo Pimentel

Filho. Belo Horizonte: Autêntica, 2012.

CAMPOS, A. e CAMPOS, H. de. (Orgs.). ReVisão de Sousândrade São Paulo: Perspectiva, 2002.

CERNICCHIARO, Ana Carolina. Sousândrade-Guesa em infern do “Wall Street": poéticas políticas. 2008. 141 f. Dissertação (Mestrado em Teoria Literária) - Centro de Comunicação e Expressão, Universidade Federal de Santa Catarina, Florianópolis, 2008.

CUCCAGNA, Claudio. A visão do ameríndio na obra de

Sousândrade. Trad. Wilma Katinsky Barreto de Souza. São Paulo: HUCITEC, 2004

DELEUZE, Gilles; GUATTARI, Félix. Mil mesetas. Capitalismo y esquizofrenia. Trad. José Vásquez Pérez y Umbelina Larraceleta. Valencia: Pre-textos, 2009

¿Qué es la filosofía? Trad. Thomas Kauf. Barcelona: Anagrama, 2011 
EAGLETON, Terry. El acontecimiento de la literatura. Trad.

Ricardo García Pérez. Barcelona: Península, 2013.

GUATTARI, Félix. Caosmosis. Trad. Irene Agoff. Buenos Aires: Manantial, 1996.

LIMA, Luiz Costa. O campo visual de uma experiência antecipadora: Sousândrade. In: CAMPOS, Augusto; CAMPOS, Haroldo. ReVisão de Sousândrade. São Paulo: Perspectiva, 2002. p. 461-503.

LÓPEZ NUÑEZ, Cesar Augusto. Experimentar con la literatura desde un pensamiento otro. Em Tese. Belo Horizonte. Vol. 21, № 23, p. 119-129, set-dez 2015. Disponível em: http:// www.periodicos.letras.ufmg.br/index.php/emtese/article/ view/9800/9635. Acesso em: 25 jul. 2016.

OLIVEIRA, Rita Cássia de. 0 poema 0 Guesa, de Sousândrade, à luz da hermenêutica de Paul Ricoeur. São Paulo: PUC, 2009.

178 f. Tese (Doutorado) - Programa de Pós-Graduação em Filosofia, Pontifícia Universidade Católica de São Paulo. São Paulo, 2009.

PEREIRA, Danglei de Castro. Tradição e modernidade em Sousândrade. 2003. 109 f. Dissertação (Mestrado) - Instituto de Biociências, Letras e Ciências Exatas, Universidade Estadua Paulista. São José do Rio Preto, 2003.

SOUSÂNDRADE, Joaquim de. O Guesa. Introdução, organização notas, glossário, fixação e atualização do texto da edição londrina, Luiza Lobo; Revisão técnica, Jomar Moraes. Rio de Janeiro: Ponteio; São Luís, MA: Academia Maranhense de

Letras, 2012
VIANA DA SILVA, Ruth Aparecida. Ecos ameríndios em Sousândrade. 2014. 124 f. Dissertação (Mestrado em Estudos Literários) - Departamento de Línguas Vernáculas. Universidade Federal de Rondônia, Porto Velho, 2014

VIVEIROS DE CASTRO, Eduardo. Metafísicas caníbales. Línea de antropología postestructural. Trad. Stella Mastrangelo. Madrid: Katz, 2010

WILLIAMS, Frederick G. Sousândrade: vida e obra. Maranhão: SIOGE, 1976 